\title{
Odor response adaptation in Drosophila—a continuous individualization process
}

\author{
Shadi Jafari ${ }^{1} \cdot$ Mattias Alenius $^{2}$ (1) \\ Received: 1 October 2020 / Accepted: 6 December 2020 / Published online: 25 January 2021 \\ (c) The Author(s) 2021
}

\begin{abstract}
Olfactory perception is very individualized in humans and also in Drosophila. The process that individualize olfaction is adaptation that across multiple time scales and mechanisms shape perception and olfactory-guided behaviors. Olfactory adaptation occurs both in the central nervous system and in the periphery. Central adaptation occurs at the level of the circuits that process olfactory inputs from the periphery where it can integrate inputs from other senses, metabolic states, and stress. We will here focus on the periphery and how the fast, slow, and persistent (lifelong) adaptation mechanisms in the olfactory sensory neurons individualize the Drosophila olfactory system.
\end{abstract}

Keywords Drosophila $\cdot$ Olfactory perception $\cdot$ Odorant

\section{OSN adaptation sites}

Odorant or pheromone molecules bind chemoreceptors localized on specialized signaling organelles of olfactory sensory neurons (OSNs) called cilia (Benton et al. 2006). Insects have three different types of chemoreceptors: odorant receptors (ORs, Clyne et al. 1999; Vosshall et al. 1999), gustatory receptors (GRs, Scott et al. 2001), and ionotropic receptors (IRs, Benton et al. 2009). Most OSNs express one odor-specific OR (Couto et al. 2005) along with the olfactory co-receptor Orco (Larsson et al. 2004), which is highly conserved across insect species (Jones et al. 2005). Each of the 20-100 OSNs that express the same receptor form synapses in the antennal lobe of the brain with an average of three excitatory projection neurons (PNs) and local interneurons (LNs) (Ng et al. 2002). The synapses of each OSN class together form one of 52 separate glomeruli with stereotypic location, shape, and size in the Drosophila antennal lobe brain region (Couto et al. 2005; Fishilevich and Vosshall 2005). Each class of OSNs localize to restricted antenna regions. Like this, the odorant plumes reach all OSNs in a class almost simultaneously, leading to synchrony in OSN responses. The convergence

Mattias Alenius

mattias.alenius@umu.se

1 Department of Biology, New York University, New York, NY, USA

2 Department of Molecular Biology, Umeå University, 90187 Umeå, SE, Sweden coupled with synchrony in olfactory responses forms a coincidence filter that increases the signal-to- noise ratio ( $\mathrm{Ng}$ et al. 2002).

Adaptive restrictions on olfactory transduction and OR response thresholds broaden the informative odorant concentration range and reduce information flow through olfactory circuits. Only ORs, but not GRs or IRs, seem subject to adaptation (Getahun et al. 2012). Beside odor transduction, synapse activity adaptation is the major adaptation site in OSNs and the first with direct retrograde input from the brain.

\section{Fast adaptation}

The fast adaptation process is cell autonomous and last minutes. The fast mechanisms divide into short and long term. Shortterm adaptation acts within seconds and fine tunes transduction and synapse activity (Cafaro 2016; Kadakia and Emonet 2019; Nagel and Wilson 2011). Long-term adaptation responds to the background odorant level and suppresses transduction on a time scale of multiple seconds (Table 1, Martelli and Fiala 2019).

\section{Short-term fast adaptation}

Short-term fast adaptation influences OR channel opening times and proceeds through the olfactory co-receptor Orco (Getahun et al. 2012). A brief odor stimulus activates 
PKC, which phosphorylates Orco and increases odor responses (Fig. 1a, Getahun et al. 2016; Guo et al. 2017). This phosphorylation of Orco by PKC is required for odor source localization in flying Drosophila (Getahun et al. 2016; Guo et al. 2017), supporting its role as a mechanism of short-term acute adaptation. In addition to its phosphorylation sites, Orco contains a conserved calmodulin interaction motif (Getahun et al. 2016) that supports ciliary transport of Orco in a direct feedback mechanism (Fig. 1a, Bahk and Jones 2016; Mukunda et al. 2014; Mukunda et al. 2016). It remains to be established whether these PKC-mediated and calmodulin-mediated mechanisms are related.

Of the five PKCs in Drosophila, Pkc53E and $P k c \delta$ increase OR sensitivity (Getahun et al. 2016). Calcium regulates Pkc53E, but not $\mathrm{Pkc} \delta$, which is downstream of GPCR signaling (Lipp and Reither 2011). Brief odor responses induce GPCR signaling, as $G q \alpha$ subunit mutant flies have reduced odor response kinetics (Kain et al. 2008). Drosophila ORs are seven transmembrane but with a reversed topology and it is debated if they are GPCRs
(Benton et al. 2006). One alternative GPCR candidate is the Hedgehog pathway. Hedgehog signals through the GPCR smoothened, which regulates PKC (Teperino et al. 2014). Smoothened is localized to OSN cilia where it regulates OR transport to the ciliary membrane (Kuzhandaivel et al. 2014; Sanchez et al. 2016). OSNs release Hedgehog, which increases odor responses (Sanchez et al. 2016). Whether the release of Hedgehog is coupled to OSN activity remains to be investigated.

\section{Long-term fast adaptation}

Strong and prolonged odor responses dephosphorylate Orco and suppress subsequent odor responses (Guo et al. 2017). The kinetics of this phenomenon indicate a tight link to activity and suggest a calcium-induced phosphatase (Fig. 1a), but the responsible phosphatase is not yet identified. Interestingly, mutants of another G-protein, G $\alpha s$, show delayed odorant response desensitization (Deng et al. 2011), and odor response kinetics
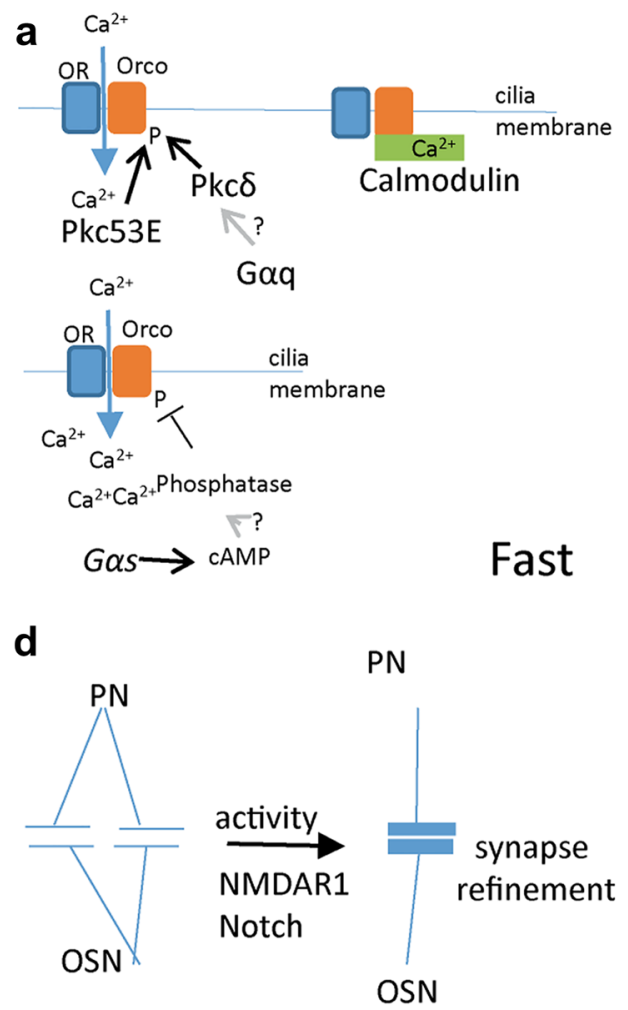

Persistent

Synaptic

Critical period b

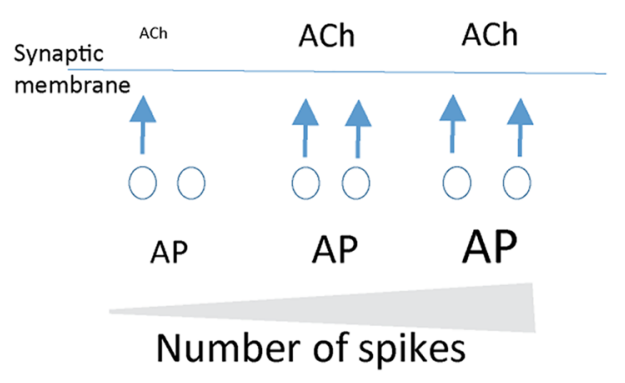

Fast

e

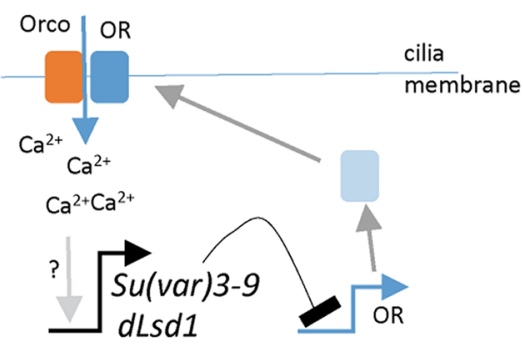

Persistent

OR expression

Critical period

Fig. 1 Direct feedback mechanism 
also affect cAMP levels (Miazzi et al. 2016; Smart et al. 2008). This suggests that different GPCR pathways may act in opposition to balance fast olfactory adaptation.

Activity at OSN/PN synapses also shows fast adaptation. PNs respond strongest to small, sharp changes in signaling from OSNs rather than to the overall size of the response (Nagel and Wilson 2011). This non-linearity arises from the limited transmitter vesicle pool available in OSN terminals; a short spike train releases all the available transmitter and any subsequent increase in spike production releases less transmitter (Fig. 1b). This increased sensitivity to change allows PNs to respond with faster kinetics than OSNs.

\section{Slow adaptation}

Slow adaptation contrasts to fast adaptation being non-cell autonomous and can shift responses between OSN classes (Table 1). The slow adaptation primarily modulates presynaptic transmission, but extended odor exposures also lead to post-synaptic PN adaptation (Cafaro 2016; Nagel et al. 2015). GABA signaling underlies most slow adaptation (Fig. 1c, Olsen and Wilson 2008; Wilson and Laurent 2005). GABAergic LNs form synapses with OSNs (Olsen and Wilson 2008; Root et al. 2008; Wilson and Laurent 2005), and the various OSN classes differ in GABA sensitivity (Grabe et al. 2020; Hong and Wilson 2015). The size of the GABA response relates to the size of the odor response, with larger responses acting to dampen extreme OSN/PN activity (Grabe et al. 2020; Olsen and Wilson 2008). This suppression results in a gain control mechanism that increases the dynamic range of information transmission (Olsen and Wilson 2008; Root et al. 2008; Wilson and Laurent 2005).

GABAergic LNs also produce the neuropeptide tachykinin (TK) (Ignell et al. 2009). High levels of OSN activity increase TK release (Winther and Ignell 2010), causing the TK receptor signal to mediate presynaptic hyperpolarization (Fig. 1c), which then contributes to presynaptic gain control (Ignell et al. 2009). OSNs also release a neuropeptide, SNPF, that, in contrast to GABA and TK signaling, increases presynaptic calcium responses (Fig. 1c, Root et al. 2011). The OSN $s N P F$ and the $G A B A B R 2$ receptor expression overlap partially (Carlsson et al. 2010). Skewing the balance between GABA and sNPF signaling can thus alter OSN inputs to the antennal lobe. During starvation, OSNs increase the expression of the SNPF and TK receptors, which enhance the contrast between negative and positive odor responses and increase attraction to food odors (Ko et al. 2015; Mohamed et al. 2019). If activity regulates sNPF and balances the OSN activity level remains to be addressed.

\section{Critical periods, a lifelong persistent adaptation}

Adult flies emerge with a naïve sensory system whose receptor expression and synaptic activity levels are not necessarily in sync with the environment. Coarse tuning of many sensory systems takes place during a restricted “critical period" (Hensch 2004). Critical periods for adaptation are distinguished from ongoing synaptic plasticity by the following criteria: they (i) have a distinct time and duration, (ii) are sensitive to experience and neuronal activity, (iii) lead to permanent changes, (iv) induce competition within the system that generates refinement, and (v) have a defined mechanism (Hensch 2004). Drosophila OSNs have two parallel and likely unrelated critical periods, one that refines OSN/ PN synapses (Fig. 1d) and another that adjusts OR levels (Fig. 1e, Table 1, Devaud et al. 2001; Golovin et al. 2019; Jafari and Alenius 2020).

Table 1 Background odorant level

\begin{tabular}{|c|c|c|c|c|c|c|}
\hline & Initiation & Duration & Tuning & $\begin{array}{l}\text { Cell } \\
\text { autono- } \\
\text { mous }\end{array}$ & Adapted step & Mechanism \\
\hline $\begin{array}{l}\text { Critical period (OR } \\
\text { expression) }\end{array}$ & First days in life & Weeks & $\begin{array}{l}\text { Coarse baseline forma- } \\
\text { tion }\end{array}$ & Yes & Transduction & $\begin{array}{l}\text { OR expression modula- } \\
\text { tion }\end{array}$ \\
\hline $\begin{array}{l}\text { Critical period (synapse } \\
\text { refinement) }\end{array}$ & First days in life & Weeks & $\begin{array}{l}\text { Coarse baseline forma- } \\
\text { tion }\end{array}$ & No & Synapse & Synapse stability \\
\hline Slow & $\begin{array}{l}\text { Minutes to } \\
\text { hours after } \\
\text { response }\end{array}$ & Hours to days & Modulation & No & Synaptic activity & $\begin{array}{l}\text { Negative: GABA, TK } \\
\text { positive: } \mathrm{sNPF}\end{array}$ \\
\hline Fast (long term) & Immediate & Seconds to minutes & Fine & Yes & Transduction & OR/Orco cilia transport \\
\hline Fast (short term) & Immediate & Seconds & Fine & Yes & Transduction & Orco phosphorylation \\
\hline
\end{tabular}




\section{Critical period for OSN synapse formation}

OSNs make permanent, activity-dependent changes to their synaptic connections with PNs and LNs during the first 3 days of adult life (Devaud et al. 2001). Studies activating a specific OSN class show distinct changes from studies where the activity comes from another OSN class (Fig. 1d, Devaud et al. 2001; Golovin et al. 2019). This suggests an interdependence between OSN classes, but direct competition between glomeruli has not yet been addressed. Nevertheless, OSN/PN synaptic adjustments are cell autonomous and require both NMDAR1/glutamate and Notch signaling (Golovin et al. 2019; Kidd et al. 2015). The OSN/PN critical period is followed by extensive adaptation and another critical period for the refinement of LN/PN synapses (Chodankar et al. 2020; Das et al. 2011; Sachse et al. 2007). These synaptic critical periods thus balance inputs and outputs.

\section{Critical period for OR expression}

OR expression in Drosophila is generally considered a static (Imai et al. 2010), predetermined process, but there is considerable plasticity in the levels of OR, GR, and IR expression in the antenna for the first 2 days of an adult fly's life (Jafari and Alenius 2020). This chemoreceptor expression plasticity also fulfills the criteria for a critical period. In these first 2 days, not only does the odor environment modulate OR expression (Iyengar et al. 2010; Koerte et al. 2018; von der Weid et al. 2015), but OR overexpression can also suppress endogenous OR expression (Fig. 1e, Jafari and Alenius 2020). This indicates a direct competition between ORs in the regulation of their expression. Interestingly, activity regulates odorant-responsive and pheromone-responsive OSNs differently (Jafari and Alenius 2020). OR expression is also stress-sensitive, with the stress-induced changes becoming permanent if the stress lasts beyond the critical period. Thus, both stress and environmental odors set the baseline for OR expression throughout a fly's life.

The mechanisms underlying the OR gene regulatory critical period build on heterochromatin regulation in ways that are similar to the OR choice mechanism in mouse olfactory neurons (Jafari and Alenius 2020; Monahan and Lomvardas 2015). In non-OSNs in Drosophila, OR genes are embedded in heterochromatin marked with $\mathrm{H} 3 \mathrm{~K} 9$ me3 produced by $\mathrm{Su}(\mathrm{var}) 3-9$, which prevents OR expression (Gonzalez et al. 2019; Jafari and Alenius 2015; Sim et al. 2012). Consistent with this, the H3K9me3 erasing enzyme $\mathrm{Kdm} 4 \mathrm{~b}$, which open heterochromatin, initiates OR expression. A second enzyme, dLsd1, removes the remaining $\mathrm{H} 3 \mathrm{~K} 9$ methylation and further establishes OR expression (Jafari and Alenius 2020). OR activity induces and balances these enzymes to modulate OR expression (Fig. 1e, Jafari and Alenius 2020) until a balance between activity and OR expression level is achieved. Thus, this feedback system functions as a rheostat that ensures olfactory responses to be within physiological limits, avoiding hyperactivation of the olfactory system. Stress suppresses activity-induced heterochromatin formation and promotes OR expression. The fact that a similar feedback mechanism is found in vertebrates (Abdus-Saboor et al. 2016; von der Weid et al. 2015) and that OR activity suppress OR expression also in mosquitoes (Maguire et al. 2020) suggests that environmental odors and stress can set OR expression baselines across phyla. A clearer picture of the mechanisms that maintain OR expression in the adult is required to understand how the acute and extended adaptation pathways set, maintain, and change the OR expression baseline.

\section{Concluding remarks and future perspectives}

Olfactory adaptation determines the beginning of each new olfactory percept and influences future percepts as well. Each adaptation step reflects the fly's earlier olfactory history. From the coarse early refinement to the continuous real-time adjustments, these adaptive mechanisms individualize a fly's olfactory responses. To limit these differences in adaptation and minimize variability in our studies, we use standardized fly housing and handling conditions. Thus, a feasible next step is to introduce specific variabilities and define how previous exposure to odor or stress alter the acute effects.

Several technical aspects must be considered when attempting to further study the mechanisms of olfactory adaptation. Thus far, most adaptation studies focused on a few OSN classes. Now, with the development of sensitive calcium and chloride imaging techniques, presynaptic adaptation can be analyzed across all classes at a millisecond time scale. Large-scale transduction studies have been limited by the array of mixed OSN classes on the antennal surface combined with the low spatial resolution of imaging techniques. Nevertheless, tour de force studies have recently pushed back at these limitations (Grabe et al. 2020; Seki et al. 2017). Ultimately, future studies must provide the necessary spatial resolution to observe the filtering that takes place between OSN classes at all stages of adaptation.

The Drosophila model itself is also a major technical hurdle that must be overcome. The many genetic tools developed in Drosophila lack the temporal resolution to match the kinetics of olfactory adaptation. Acute adaptation takes place on the scale of milliseconds to minutes, while existing temporally controlled genetic techniques function over the course of days. Alternative tools that can follow 
the process live may solve some of these many temporal issues. The phospho-Orco antibody (Guo et al. 2017), for example, shows that the next generation of tools need not be driven by high technology, just well-suited to the specific mechanism of interest. An alternative is machine learning algorithms and mathematical models of electrophysiological measurements (Kadakia and Emonet 2019; Nagel et al. 2015), which may help bridge the static results of genetic studies and the dynamics of adaptation.

Here, we have discussed how OSNs, rather than being mere input channels, represent a filter and that the filter is prone to changes. Therefore, to understand the central olfactory processing, the peripheral filtering of olfactory inputs at the level of the OSNs must be taken into account and understood. Thus, the time has come to tweak our assays to get a richer picture of the olfactory life of Drosophila and other species.

Funding Open Access funding provided by Umea University This work was supported by the Swedish Research foundation, grant (2016-05208).

\section{Compliance with ethical standards}

Conflict of interest The authors declare that they have no conflict of interest.

Ethical approval This article does not contain any studies with human participants or animals performed by any authors.

Open Access This article is licensed under a Creative Commons Attribution 4.0 International License, which permits use, sharing, adaptation, distribution and reproduction in any medium or format, as long as you give appropriate credit to the original author(s) and the source, provide a link to the Creative Commons licence, and indicate if changes were made. The images or other third party material in this article are included in the article's Creative Commons licence, unless indicated otherwise in a credit line to the material. If material is not included in the article's Creative Commons licence and your intended use is not permitted by statutory regulation or exceeds the permitted use, you will need to obtain permission directly from the copyright holder. To view a copy of this licence, visit http://creativecommons.org/licenses/by/4.0/.

\section{References}

Abdus-Saboor I, Al Nufal MJ, Agha MV, Ruinart de Brimont M, Fleischmann A, Shykind BM (2016) An expression refinement process ensures singular odorant receptor gene choice. Curr Biol 26:1083-1090

Bahk S, Jones WD (2016) Insect odorant receptor trafficking requires calmodulin. BMC Biol 14:83

Benton R, Sachse S, Michnick SW, Vosshall LB (2006) Atypical membrane topology and heteromeric function of Drosophila odorant receptors in vivo. Plos Biol 4:e20

Benton R, Vannice KS, Gomez-Diaz C, Vosshall LB (2009) Variant ionotropic glutamate receptors as chemosensory receptors in Drosophila. Cell 136:149-162
Cafaro J (2016) Multiple sites of adaptation lead to contrast encoding in the Drosophila olfactory system. Physiol Rep 4

Carlsson MA, Diesner M, Schachtner J, Nassel DR (2010) Multiple neuropeptides in the Drosophila antennal lobe suggest complex modulatory circuits. J Comp Neurol 518:3359-3380

Chodankar A, Sadanandappa MK, VijayRaghavan K, Ramaswami M (2020) Glomerulus-selective regulation of a critical period for interneuron plasticity in the Drosophila antennal lobe. J Neurosci 40:5549-5560

Clyne PJ, Warr CG, Freeman MR, Lessing D, Kim J, Carlson JR (1999) A novel family of divergent seven-transmembrane proteins: candidate odorant receptors in Drosophila. Neuron 22:327-338

Couto A, Alenius M, Dickson BJ (2005) Molecular, anatomical, and functional organization of the Drosophila olfactory system. Curr Biol 15:1535-1547

Das S, Sadanandappa MK, Dervan A, Larkin A, Lee JA, Sudhakaran IP, Priya R, Heidari R, Holohan EE, Pimentel A et al (2011) Plasticity of local GABAergic interneurons drives olfactory habituation. Proc Natl Acad Sci U S A 108:E646-654

Deng Y, Zhang W, Farhat K, Oberland S, Gisselmann G, Neuhaus EM (2011) The stimulatory Galpha(s) protein is involved in olfactory signal transduction in Drosophila. PLoS ONE 6:e18605

Devaud JM, Acebes A, Ferrus A (2001) Odor exposure causes central adaptation and morphological changes in selected olfactory glomeruli in Drosophila. J Neurosci 21:6274-6282

Fishilevich E, Vosshall LB (2005) Genetic and functional subdivision of the Drosophila antennal lobe. Curr Biol 15:1548-1553

Getahun MN, Thoma M, Lavista-Llanos S, Keesey I, Fandino RA, Knaden M, Wicher D, Olsson SB, Hansson BS (2016) Intracellular regulation of the insect chemoreceptor complex impacts odour localization in flying insects. J Exp Biol 219:3428-3438

Getahun MN, Wicher D, Hansson BS, Olsson SB (2012) Temporal response dynamics of Drosophila olfactory sensory neurons depends on receptor type and response polarity. Front Cell Neurosci 6:54

Golovin RM, Vest J, Vita DJ, Broadie K (2019) Activity-dependent remodeling of Drosophila olfactory sensory neuron brain innervation during an early-life critical period. J Neurosci 39:2995-3012

Gonzalez A, Jafari S, Zenere A, Alenius M, Altafini C (2019) Thermodynamic model of gene regulation for the Or59b olfactory receptor in Drosophila. PLoS Comput Biol 15:e1006709

Grabe V, Schubert M, Strube-Bloss M, Reinert A, Trautheim S, Lavista-Llanos S, Fiala A, Hansson BS, Sachse S (2020) OdorInduced Multi-Level Inhibitory Maps in Drosophila. eNeuro 7

Guo H, Kunwar K, Smith D (2017) Odorant receptor sensitivity modulation in Drosophila. J Neurosci 37:9465-9473

Hensch TK (2004) Critical period regulation. Annu Rev Neurosci 27:549-579

Hong EJ, Wilson RI (2015) Simultaneous encoding of odors by channels with diverse sensitivity to inhibition. Neuron 85:573-589

Ignell R, Root CM, Birse RT, Wang JW, Nassel DR, Winther AM (2009) Presynaptic peptidergic modulation of olfactory receptor neurons in Drosophila. Proc Natl Acad Sci USA 106:13070-13075

Imai T, Sakano H, Vosshall LB (2010) Topographic mapping-the olfactory system. Cold Spring Harb Perspect Biol 2:a001776

Iyengar A, Chakraborty TS, Goswami SP, Wu CF, Siddiqi O (2010) Post-eclosion odor experience modifies olfactory receptor neuron coding in Drosophila. P Natl Acad Sci USA 107:9855-9860

Jafari S, Alenius M (2015) Cis-regulatory mechanisms for robust olfactory sensory neuron class-restricted odorant receptor gene expression in Drosophila. Plos Genet 11:e1005051

Jafari S, Alenius M (2020). Activity and stress during a critical period regulate olfactory sensory neuron differentiation. https://doi. org/10.1101/2021.01.13.426514 
Jones WD, Nguyen TA, Kloss B, Lee KJ, Vosshall LB (2005) Functional conservation of an insect odorant receptor gene across 250 million years of evolution. Curr Biol 15:R119-121

Kadakia N, Emonet T (2019) Front-end Weber-Fechner gain control enhances the fidelity of combinatorial odor coding. Elife 8

Kain P, Chandrashekaran S, Rodrigues V, Hasan G (2008) Drosophila mutants in phospholipid signaling have reduced olfactory responses as adults and larvae. J Neurogenet 1-10

Kidd S, Struhl G, Lieber T (2015) Notch is required in adult Drosophila sensory neurons for morphological and functional plasticity of the olfactory circuit. Plos Genet 11:e1005244

Ko KI, Root CM, Lindsay SA, Zaninovich OA, Shepherd AK, Wasserman SA, Kim SM, Wang JW (2015) Starvation promotes concerted modulation of appetitive olfactory behavior via parallel neuromodulatory circuits. Elife 4

Koerte S, Keesey IW, Khallaf MA, Llorca LC, Grosse-Wilde E, Hansson BS, Knaden M (2018) Evaluation of the DREAM Technique for a High-Throughput Deorphanization of Chemosensory Receptors in Drosophila. Front Mol Neurosci 11

Kuzhandaivel A, Schultz SW, Alkhori L, Alenius M (2014) Ciliamediated hedgehog signaling in Drosophila. Cell Rep 7:672-680

Larsson MC, Domingos AI, Jones WD, Chiappe ME, Amrein H, Vosshall LB (2004) Or83b encodes a broadly expressed odorant receptor essential for Drosophila olfaction. Neuron 43:703-714

Lipp P, Reither G (2011) Protein kinase C: the "masters" of calcium and lipid. Cold Spring Harb Perspect Biol 3

Maguire SE, Afify A, Goff LA, Potter CJ (2020) A Feedback Mechanism Regulates Odorant Receptor Expression in the Malaria Mosquito, Anopheles gambiae. bioRxiv, 2020.2007.2023.218586

Martelli C, Fiala A (2019) Slow presynaptic mechanisms that mediate adaptation in the olfactory pathway of Drosophila. Elife 8

Miazzi F, Hansson BS, Wicher D (2016) Odor-induced cAMP production in Drosophila melanogaster olfactory sensory neurons. J Exp Biol 219:1798-1803

Mohamed AAM, Retzke T, Das Chakraborty S, Fabian B, Hansson BS, Knaden M, Sachse S (2019) Odor mixtures of opposing valence unveil inter-glomerular crosstalk in the Drosophila antennal lobe. Nat Commun 10:1201

Monahan K, Lomvardas S (2015) Monoallelic expression of olfactory receptors. Annu Rev Cell Dev Biol 31:721-740

Mukunda L, Miazzi F, Kaltofen S, Hansson BS, Wicher D (2014) Calmodulin modulates insect odorant receptor function. Cell Calcium 55:191-199

Mukunda L, Miazzi F, Sargsyan V, Hansson BS, Wicher D (2016) Calmodulin affects sensitization of Drosophila melanogaster odorant receptors. Front Cell Neurosci 10:28

Nagel KI, Hong EJ, Wilson RI (2015) Synaptic and circuit mechanisms promoting broadband transmission of olfactory stimulus dynamics. Nat Neurosci 18:56-65

Nagel KI, Wilson RI (2011) Biophysical mechanisms underlying olfactory receptor neuron dynamics. Nat Neurosci 14:208-216
Ng M, Roorda RD, Lima SQ, Zemelman BV, Morcillo P, Miesenbock $G$ (2002) Transmission of olfactory information between three populations of neurons in the antennal lobe of the fly. Neuron 36:463-474

Olsen SR, Wilson RI (2008) Lateral presynaptic inhibition mediates gain control in an olfactory circuit. Nature 452:956-960

Root CM, Ko KI, Jafari A, Wang JW (2011) Presynaptic facilitation by neuropeptide signaling mediates odor-driven food search. Cell 145:133-144

Root CM, Masuyama K, Green DS, Enell LE, Nassel DR, Lee CH, Wang JW (2008) A presynaptic gain control mechanism fine-tunes olfactory behavior. Neuron 59:311-321

Sachse S, Rueckert E, Keller A, Okada R, Tanaka NK, Ito K, Vosshall LB (2007) Activity-dependent plasticity in an olfactory circuit. Neuron 56:838-850

Sanchez GM, Alkhori L, Hatano E, Schultz SW, Kuzhandaivel A, Jafari S, Granseth B, Alenius M (2016) Hedgehog signaling regulates the ciliary transport of odorant receptors in Drosophila. Cell Rep 14:464-470

Scott K, Brady R Jr, Cravchik A, Morozov P, Rzhetsky A, Zuker C, Axel R (2001) A chemosensory gene family encoding candidate gustatory and olfactory receptors in Drosophila. Cell 104:661-673

Seki Y, Dweck HKM, Rybak J, Wicher D, Sachse S, Hansson BS (2017) Olfactory coding from the periphery to higher brain centers in the Drosophila brain. BMC Biol 15:56

Sim CK, Perry S, Tharadra SK, Lipsick JS, Ray A (2012) Epigenetic regulation of olfactory receptor gene expression by the MybMuvB/dREAM complex. Genes Dev 26:2483-2498

Smart R, Kiely A, Beale M, Vargas E, Carraher C, Kralicek AV, Christie DL, Chen C, Newcomb RD, Warr CG (2008) Drosophila odorant receptors are novel seven transmembrane domain proteins that can signal independently of heterotrimeric $G$ proteins. Insect Biochem Mol Biol 38:770-780

Teperino R, Aberger F, Esterbauer H, Riobo N, Pospisilik JA (2014) Canonical and non-canonical Hedgehog signalling and the control of metabolism. Semin Cell Dev Biol 33:81-92

von der Weid B, Rossier D, Lindup M, Tuberosa J, Widmer A, Col JD, Kan C, Carleton A, Rodriguez I (2015) Large-scale transcriptional profiling of chemosensory neurons identifies receptor-ligand pairs in vivo. Nat Neurosci 18:1455-1463

Vosshall LB, Amrein H, Morozov PS, Rzhetsky A, Axel R (1999) A spatial map of olfactory receptor expression in the Drosophila antenna. Cell 96:725-736

Wilson RI, Laurent G (2005) Role of GABAergic inhibition in shaping odor-evoked spatiotemporal patterns in the Drosophila antennal lobe. J Neurosci 25:9069-9079

Winther AM, Ignell R (2010) Local peptidergic signaling in the antennal lobe shapes olfactory behavior. Fly (Austin) 4:167-171

Publisher's Note Springer Nature remains neutral with regard to jurisdictional claims in published maps and institutional affiliations. 